\title{
Research on Airport Security Based on Virtual Queuing Theory
}

\author{
Yaxin Liu \\ North China Electric Power University, Baoding, Hebei Province, China \\ 18730266367@163.com
}

\begin{abstract}
Airport screening process takes too long time and people take more attention to this phenomenon and hope it to be solved. In this paper, we propose virtual queuing model in order to minimize the average waiting time, minimum waiting time variance and to ensure the airline's maximum revenue. By establishing a virtual queuing simulation model, we calculate security process waiting time in the conditions of no-virtual queuing, partial virtual queuing and full virtual queuing. Then, we compare the results in under the different circumstances. At the end, we come to a conclusion that the use of virtual queuing mode can effectively reduce passengers' waiting time, increase passenger throughput and increase passengers' satisfaction.
\end{abstract}

Key words: virtual queuing model; maximum revenue; no-virtual; circumstances; effectively reduce; passengers' satisfaction.

\section{INTRODUCTION}

Virtual queue is to add a virtual queue in the original queue. It's that the passengers are not queued in the normal queue, but he can occupy a position in the queue through software and reach the queue within the time specified by the virtual queuing system. otherwise the queue is disqualified, as shown in Fig. 1:
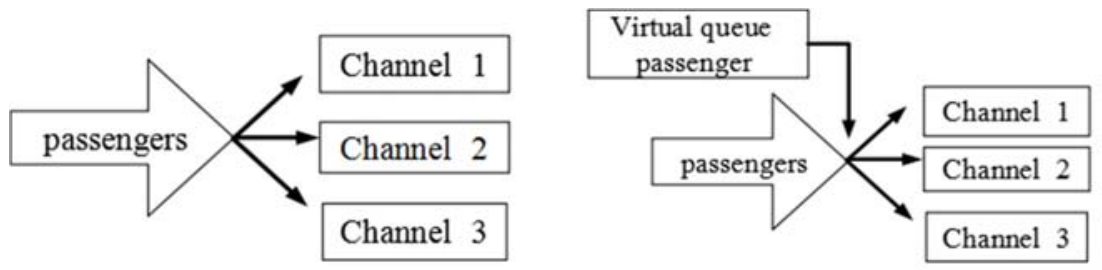

FIGURE 1. Comparison of normal queues and virtual queues

\section{ESTABLISHMENT OF VIRTUAL QUEUING MODEL}

Based on the analysis of the traditional queuing theory, Robert takes the European airport as the research object and obtained the factors of virtual queuing and proposed the virtual queuing model to reduce the airport security cost and improve the airport efficiency [4]. Therefore, here we will be specific about how the virtual queuing model to enhance the efficiency of the case. 


\section{Case Analysis.}

Taking the airport security data in Table 1 as an example, a virtual queuing model is established to analyze and calculate the data under the basic assumptions, and the results are compared with the actual airport security data.

TABLE 1. An airport security data

\begin{tabular}{|c|c|c|c|c|c|}
\hline $\begin{array}{c}\text { The time } \\
\text { interval }\end{array}$ & $\begin{array}{c}\text { The number } \\
\text { of arrivals }\end{array}$ & $\begin{array}{c}\text { The number of } \\
\text { open security } \\
\text { channel }\end{array}$ & $\begin{array}{c}\text { The number of } \\
\text { passengers per } \\
\text { security } \\
\text { channel }\end{array}$ & $\begin{array}{c}\text { Actual arrival rate } \\
\text { of each channel }\end{array}$ & $\begin{array}{c}\text { Each channel } \\
\text { actual service } \\
\text { rate }\end{array}$ \\
\hline $9: 00-9: 30$ & 1361 & 9 & 151 & 5.03 & 2.67 \\
\hline $9: 30-10: 00$ & 1524 & 10 & 152 & 5.07 & 2.67 \\
\hline $10: 30-11: 00$ & 1644 & 11 & 149 & 4.97 & 2.67 \\
\hline $11: 00-11: 30$ & 1511 & 10 & 150 & 5.00 & 2.67 \\
\hline $11: 30-12: 00$ & 1508 & 10 & 151 & 5.04 & 2.67 \\
\hline
\end{tabular}

\section{Basic Prerequisites.}

In order to facilitate the calculation, we select the peak hours of 9: 00-12: 00 passengers' waiting time for the study and the average queue length $\mathrm{N}$, from the data available $\mathrm{N}$ is about 150 , so this article will discuss the questions at the team length of 150 .

\section{Virtual Queuing Simulation Flow.}

The flow chart of virtual queuing operation in MATLAB is as follows:

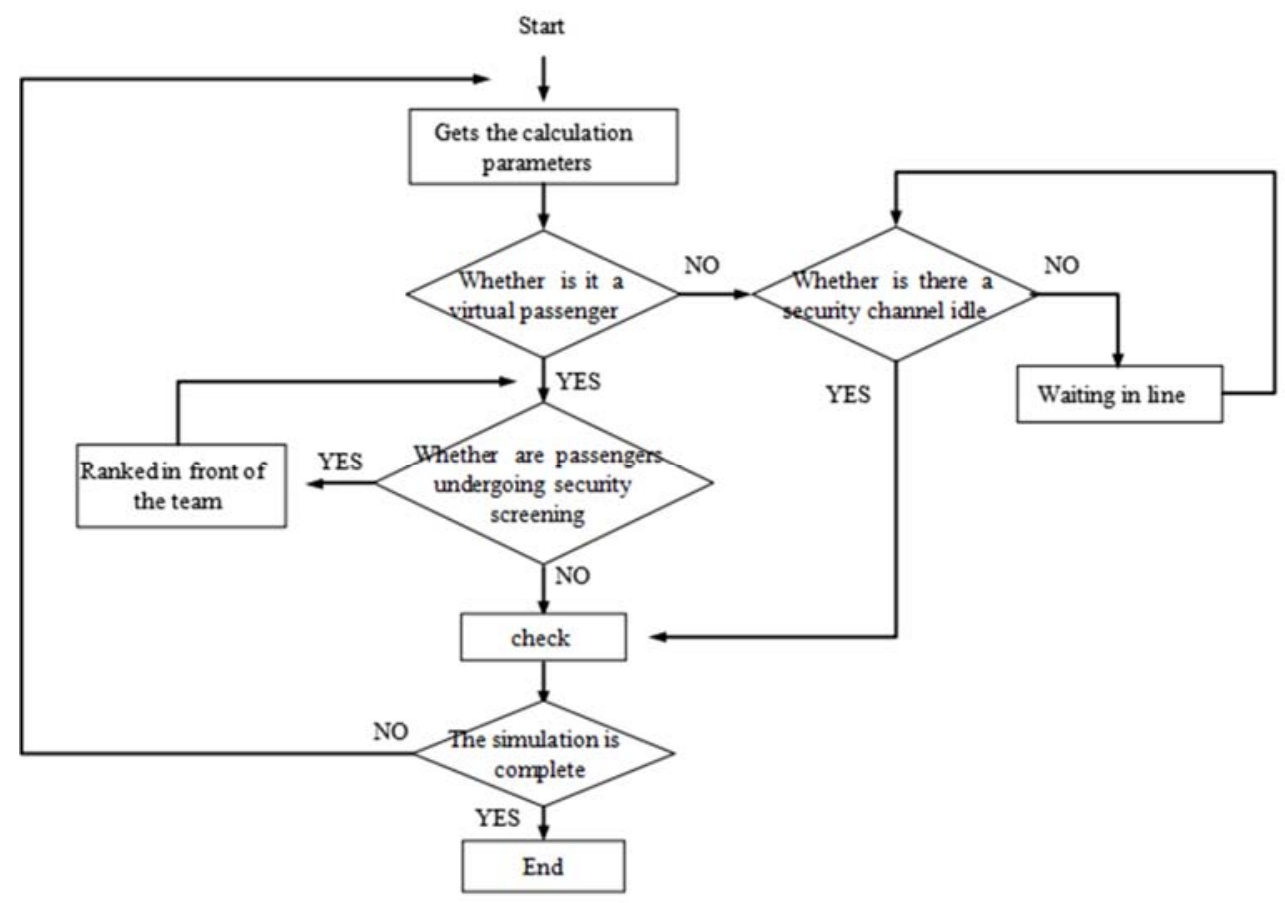

FIGURE 2. Flow chart of virtual queuing operation 


\section{The Case of Virtual Queuing Simulation is not Implemented.}

Passengers' waiting time without virtual queuing is simulated based on real survey data, so in this case the passengers' flight time is taken into account, and all the passengers are ordinary passengers, there is no virtual queuing passengers. Passengers in the security process in accordance with the principle of first-come first-line wait for security check. According to the arrival rate of passengers, the service rate of security personnel and the maximum queuing theory, the waiting time of passengers is simulated by MATLAB. The simulation results are shown in Table 2.

TABLE 2. Waiting times for non-virtual queuing passengers

\begin{tabular}{|c|c|c|c|}
\hline & $\begin{array}{c}\text { The average number of } \\
\text { ordinary passengers } \\
\text { waiting in channel }\end{array}$ & $\begin{array}{c}\text { Ordinary passengers' total } \\
\text { waiting time[min] }\end{array}$ & $\begin{array}{c}\text { General passengers' } \\
\text { average waiting } \\
\text { time[min] }\end{array}$ \\
\hline $09: 00-09: 30$ & 151 & 3055.45 & 20.24 \\
\hline $09: 30-10: 00$ & 152 & 3202.23 & 21.21 \\
\hline $10: 00-10: 30$ & 149 & 2999.94 & 20.13 \\
\hline $10: 30-11: 00$ & 153 & 3219.18 & 21.04 \\
\hline $11: 00-11: 30$ & 150 & 2961.85 & 19.75 \\
\hline $11: 30-12: 00$ & 151 & 3004.27 & 19.90 \\
\hline
\end{tabular}

\section{Implementation of Virtual Queuing.}

When some passengers are virtual passengers, according to the process of passenger virtual queuing, it can be seen that ordinary passengers can join the virtual queuing system by virtual queuing system. Then, the virtual queuing system can measure the passenger flow distribution during the peak period by regulating the passengers to wait for queuing, shorten the waiting time, thereby increasing the security throughput.

Because of the airport traffic, the simulation process need to determine the virtual passengers in all the proportion of passengers queuing, in order to facilitate the calculation. And $20 \%$ of the total number of passengers are determined as virtual queue of passengers. These virtual passengers will be queued in the specified time to return directly to the queue in the head position for security. Ordinary passengers still need to follow the principle of first-come-first-served queuing security.

The time for virtual queuing passengers to return to the queue is only determined by the virtual queuing system, irrespective of passengers' flight time. But in reality, in order to ensure that virtual passengers can board the plane on time, the virtual queuing process must take the flight departure time into account. Therefore, considering the passengers' flight time, the time that the virtual queuing passengers return to the queue is determined by the flight time and the virtual queuing system.

Therefore, we calculate the passengers' waiting time in two cases, regardless of flight time and considering the flight time, using MATLAB, the calculation results are shown in Table 3.

According to Table 3, the queuing time of passengers is reduced, regardless of whether or not the flight timings are taken into account, as compared with the cases where virtual queuing is not implemented. In the case of taking into account flight times, the average waiting time for passengers increases by about 1.5 minutes compared to the time without regard to the flight schedule.

All passengers are virtual queuing passengers are ideal for virtual queuing systems. In this process, the passengers' waiting time in the case of considering the flight time and not considering the flight time is calculated. the simulation is carried out by MATLAB, the results are shown in Table 4. 
TABLE 3. calculation results

\begin{tabular}{|c|c|c|c|c|c|}
\hline \multirow[b]{2}{*}{ The time interval } & \multirow{2}{*}{$\begin{array}{l}\text { The average } \\
\text { number of } \\
\text { passengers } \\
\text { waiting in } \\
\text { channel }\end{array}$} & \multicolumn{2}{|c|}{ Regardless of the flight schedules } & \multicolumn{2}{|c|}{ Considering the flight time } \\
\hline & & $\begin{array}{l}\text { All the } \\
\text { passengers' } \\
\text { waiting } \\
\text { time[min] }\end{array}$ & $\begin{array}{c}\text { The average } \\
\text { waiting } \\
\text { time[min] }\end{array}$ & $\begin{array}{c}\text { The average } \\
\text { waiting } \\
\text { time[min] }\end{array}$ & $\begin{array}{l}\text { The number of } \\
\text { flights is } \\
\text { expected }\end{array}$ \\
\hline 09:00-09:30 & 151 & 3055.45 & 12.12 & 13.33 & 6 \\
\hline 09:30-10:00 & 152 & 3202.23 & 13.16 & 14.73 & 7 \\
\hline $10: 00-10: 30$ & 149 & 2999.94 & 12.34 & 13.88 & 7 \\
\hline $10: 30-11: 00$ & 153 & 3219.18 & 13.04 & 14.49 & 8 \\
\hline $11: 00-11: 30$ & 150 & 2961.85 & 11.95 & 13.52 & 5 \\
\hline $11: 30-12: 00$ & 151 & 3004.27 & 12.04 & 13.60 & 6 \\
\hline
\end{tabular}

TABLE 4. The simulation is carried out by MATLA

\begin{tabular}{|c|c|c|c|c|c|}
\hline & \multicolumn{2}{|c|}{$\begin{array}{c}\text { The average } \\
\text { The time interval }\end{array}$} & \multicolumn{2}{|c|}{ Regardless of the flight schedules } & \multicolumn{2}{c|}{ Considering the flight time } \\
\cline { 3 - 6 } & $\begin{array}{c}\text { number of } \\
\text { passengers } \\
\text { waiting in } \\
\text { channel }\end{array}$ & $\begin{array}{c}\text { All the } \\
\text { passengers' } \\
\text { waiting } \\
\text { time[min] }\end{array}$ & $\begin{array}{c}\text { The average } \\
\text { waiting } \\
\text { time[min] }\end{array}$ & $\begin{array}{c}\text { The average } \\
\text { waiting } \\
\text { time[min] }\end{array}$ & $\begin{array}{c}\text { The number of } \\
\text { flights is } \\
\text { expected }\end{array}$ \\
\hline $09: 00-09: 30$ & 151 & 803.31 & 5.32 & 7.01 & 6 \\
\hline $09: 30-10: 00$ & 152 & 919.57 & 6.05 & 7.63 & 7 \\
\hline $10: 00-10: 30$ & 149 & 810.60 & 5.44 & 6.83 & 7 \\
\hline $10: 30-11: 00$ & 153 & 937.91 & 6.13 & 7.77 & 5 \\
\hline $11: 00-11: 30$ & 150 & 844.47 & 5.63 & 6.82 & 6 \\
\hline $11: 30-12: 00$ & 151 & 812.33 & 5.38 & 7.15 & 7 \\
\hline
\end{tabular}

\section{Comparison of Results Under Different Circumstances.}

Considering the time of flight, we contrastive analysis of the results without virtual queuing, partial passenger virtual queuing, and all passenger virtual queuing, as shown in Table 5.

As shown in Table 5, when the virtual queue is not implemented, the waiting time is about 20 minutes. Compared with the situation that the virtual queuing is not implemented; the waiting time of the passengers is reduced to a certain extent. The average waiting time is about 14 minutes, which is about $30 \%$ less than the average waiting time without virtual queuing, which is about 6 minutes when some passengers are virtual queuing passengers.so when the passengers are virtual queue of passengers, the average waiting time is about 7 minutes, which is about $65 \%$ less than the average waiting time without virtual queuing, which is about 13 minutes. 
TABLE 5. Comparison of results under different circumstances

\begin{tabular}{|c|c|c|c|c|c|}
\hline & \multicolumn{2}{|c|}{$\begin{array}{c}\text { Not to implement } \\
\text { virtual queue }\end{array}$} & \multicolumn{2}{|c|}{$\begin{array}{c}\text { Some of passengers for virtual } \\
\text { queue }\end{array}$} & \multicolumn{2}{|c|}{ All passengers for virtual queue } \\
\hline The time interval & Waiting time[min] & $\begin{array}{c}\text { Waiting } \\
\text { time[min] }\end{array}$ & $\begin{array}{c}\text { Reduce the } \\
\text { proportion } \\
{[\%]}\end{array}$ & $\begin{array}{c}\text { Waiting } \\
\text { time[min] }\end{array}$ & $\begin{array}{c}\text { Reduce the } \\
\text { proportion [\%] }\end{array}$ \\
\hline $09: 00-09: 30$ & 20.24 & 13.33 & 34.14 & 7.01 & 65.37 \\
\hline $09: 30-10: 00$ & 21.21 & 14.73 & 30.55 & 7.63 & 64.03 \\
\hline $10: 00-10: 30$ & 20.13 & 13.88 & 31.05 & 6.83 & 66.07 \\
\hline $10: 30-11: 00$ & 21.04 & 14.49 & 31.13 & 7.77 & 63.07 \\
\hline $11: 00-11: 30$ & 19.75 & 13.52 & 31.54 & 7.15 & 63.80 \\
\hline $11: 30-12: 00$ & 19.90 & 13.60 & 31.66 & 6.82 & 65.73 \\
\hline Average & 20.38 & 13.93 & 33.86 & 7.20 & 64.67 \\
\hline
\end{tabular}

\section{SUMMARY}

It can be seen that, in reality, the use of virtual queuing mode can effectively reduce passengers' waiting time, increase passenger throughput and increase passengers' satisfaction, so this has an important role in the development of the civil aviation industry.

\section{REFERENCES}

1. X.H. Liu, L. Zhang, Y. Zhao and Q. Zhang: Technology and Innovation, Vol. 35 (2017) No.9, p.125. (In Chinese).

2. Y.C. Wang, Q.C. Zhao and D.Z. Zheng: Journal of Systems Science and Systems Engineering, Vol. 14 (2005) No.3, p.347. (In Chinese).

3. X.X. Ning: The Course of Practical Operations Research (Beijing Science Press, China 2007). (In Chinese).

4. R.D. Lange, I.S. Lovich and B.D. Rhee: European Journal of Operational Research, Vol. 225 (2013) No.1, p.153.

5. J.Y. Cheng and Y. Xu: Public Safety in China, Vol.328 (2016) No.2, p.41. (In Chinese).

6. M.L. Dai, F. Jiao, X.H. Zhou and L.M. Shun: Science and Technology Market, Vol. 567 (2017) No.8, p.5. (In Chinese).

7. Z.W. Zhao and J.J. Ma: Comprehensive Transportation, Vol. 38 (2016) No.10, p.64. (In Chinese).

8. H.Y. Li, T.S. Chen, F. Yan and L.H. Yang: Economic and Trade Practice, Vol. 351 (2017) No.11, p.14. (In Chinese).

9. M.C. Sun: Journal of Huanggang Vocational and Technical College, Vol. 354 (2017) No.5, p.122. (In Chinese)

10. Z. Liu, H.Y. XUI and Y.Y. Li: Science and Technology Economic Tribune, Vol. 226 (2017) No.10, p.17. (In Chinese). 